Article

\title{
What Makes a Difference for Disadvantaged Girls? Investigating the Interplay between Group Composition and Positive Youth Development in Sport
}

\author{
Hebe Schaillée ${ }^{1, *}$, Marc Theeboom ${ }^{1}$ and Jelle Van Cauwenberg $2,3,4$ \\ ${ }^{1}$ Department of Sport Policy and Management, Vrije Universiteit Brussel, 1050 Brussels, Belgium, \\ E-Mails: hschaill@vub.ac.be (H.S.), mtheeboo@vub.ac.be (M.T.) \\ ${ }^{2}$ Department of Public Health, Ghent University, 9000 Ghent, Belgium, E-Mail: jvcauwen@vub.ac.be \\ ${ }^{3}$ Department of Human Biometry and Biomechanics, Vrije Universiteit Brussel, 1050 Brussels, Belgium \\ ${ }^{4}$ Fund for Scientific Research Flanders (FWO), 1000 Brussels, Belgium \\ * Corresponding author
}

Submitted: 3 April 2015 | In Revised Form: 10 June 2015 | Accepted: 12 June 2015 | Published: 25 June 2015

\begin{abstract}
It has been suggested that group composition can influence the experiences of individual group members in social programmes (Weiss, 1998). The purpose of the present study was to examine the relationship between peer group composition in sports programmes and positive youth development (PYD) in disadvantaged girls, as well as to determine whether it was moderated by personal characteristics. Two hundred young women aged between 10 and 24 completed a questionnaire including, among others, the "Youth Experience Survey for Sport" (YES-S) (MacDonald, Côté, Eys, \& Deakin, 2012) and questions regarding participants' socio-economic characteristics (i.e., nationality, education, family situation). Multilevel regression analyses were performed to take into account the hierarchical data structure. At the group level, a higher percentage of girls from a low educational track and with a migration background predicted greater PYD, as indicated by higher levels of personal and social skills, cognitive skills and goal setting. Results showed interaction effects between the respondents' family structures on the participant and team levels. The overall statistical models for the different developmental domains accounted for variance ranging from $14.7 \%$ (personal and social skills) to $30.3 \%$ (cognitive skills). Results indicated that the extent to which disadvantaged girls derive benefits from their participation in sport also depends on the group composition. The interaction effects between the group composition and individual characteristics suggest that when girls participate in a group of similar peers, those from non-intact families will derive more benefits than their counterparts from intact families.
\end{abstract}

\section{Keywords}

disadvantaged girls; group composition; peers; positive youth development; sport

\section{Issue}

This article is part of the special issue "Sport for Social Inclusion: Critical Analyses and Future Challenges", edited by Dr. Reinhard Haudenhuyse (Vrije Universiteit Brussel, Belgium) and Professor Marc Theeboom (Vrije Universiteit Brussel, Belgium).

(C) 2015 by the authors; licensee Cogitatio (Lisbon, Portugal). This article is licensed under a Creative Commons Attribution 4.0 International License (CC BY).

\section{Introduction}

Organised leisure activities have been described as unique learning environments that can foster positive youth development (PYD) (Holt, 2008). Participation in organised youth sport is one vehicle for PYD that is gaining increasing attention in academic literature (Holt \& Jones, 2008; Petitpas, Cornelius, Van Raalte, \& 
Jones, 2005). It has been indicated that involvement in sports in an organised context is particularly valuable for disadvantaged young people in general (e.g., Blomfield \& Barber, 2010), and could also be beneficial for disadvantaged girls in particular. To date however, there is little understanding of the developmental experiences young females in disadvantaged positions have when they participate in sport. Research in the domain of PYD has expressed the importance of studying development of youth by using an ecological perspective. Garcia Bengoechea and Johnson (2001) suggested that the process-person-context-time (PPCT) model, conceptualized by Bronfenbrenner (1999), is an appropriate framework to examine youth sport as a developmental process. According to this model, the form, power, content, and direction of the processes affecting development vary systematically as a joint function of, amongst others, (a) the developmental outcomes under consideration, (b) the environment or context in which the processes are happening and (c) the characteristics of the developing person. Disadvantaged girls are, however, involved in different sport contexts. The objective of the present study was to investigate if the context makes a difference for disadvantaged girls. In line with the factors of the PPCTmodel we will briefly review literature related to developmental outcomes (i.e., domains of learning experiences), one environmental or contextual factor (i.e., peer groups) and the characteristics of the developing persons (i.e., characteristics of disadvantaged girls) under consideration in this study.

\subsection{Domains of Learning Experiences in Sport}

To date, researchers in the PYD domain have used different theoretical approaches to explore the developmental potential of organised sport. More specifically, studies have used the $5 \mathrm{C}^{\prime}$ s measurement model (Lerner et al., 2005), the developmental assets framework (Leffert et al., 1998) and the interpersonal domains of learning experiences (Larson, Hansen, \& Moneta, 2006) to assess and evaluate the effects associated with organised participation in sport. Dworkin, Larson and Hansen's (2003) domains of learning experiences have been used extensively to study PYD in organised youth activities. They examined growth experiences among adolescents through participation in organised activities including sport which they defined as "experiences that teach you something or expand you in some way, that give you new skills, new attitudes, or new ways of interacting with others" (p. 20).

Larson et al. (2006) found that youth sport is a context for identity work, emotional regulation, and teamwork, but also that young people reported significantly more negative experiences involving negative peer interaction, inappropriate adult behaviour and stress in sport compared to other organised activities.
The authors also indicated that higher levels of involvement were associated with higher rates of learning experiences. Despite the extensive amount of published material on PYD in general (e.g., Catalano, Berglund, Ryan, Lonczak, \& Hawkins, 2004; Eccles \& Gootman, 2002; Holt, 2008; Lerner, Lerner, \& Benson, 2011; Perkins \& Le Mesenstrel, 2007), to date there has been only limited research on the experiences young people derive from taking part in organised sports activities (e.g., Bruner, Eys, Wilson, \& Côté, 2014; FraserThomas \& Côté, 2009; MacDonald et al., 2012). For example, Wilkes and Côté (2010) found differences in selfreported learning experiences among young people who participated in different sports contexts. Female youth sports participants in recreational programmes scored significantly lower in several domains of learning compared to those in competitive and school programmes. They argued that the time commitment of participants, training and background of coaches, and competition and volunteer opportunities within competitive and school sports programmes positively mediated the relationship between participation in sport and learning experiences. These findings support most PYD literature reporting that the structure of the environment should be examined in order to understand how participation is experienced by young people (Hansen \& Larson, 2007). A majority of the sport-related youth studies in the PYD domain have focused on the impact of coaches and coach-participant relationships. Research has been related, for example, to coaching behaviour (Gould \& Carson, 2011), motivational climate (Gould, Flett, \& Lauer, 2012) and caring climate (Gould et al., 2012). Although it has often been indicated that peers in organised activities (including sport) can be a positive source of influence for youth development compared to other sources (such as coaches and parents), their position has received only moderate attention from researchers (Denault \& Poulin, 2007; Holt \& Jones, 2008; Holt \& Sehn, 2008; Partridge, 2011; Smith, 2003).

\subsection{Peer Groups}

According to Denault and Poulin (2007), very few studies have examined peer relations in organised sports programmes. There are some studies that have examined the quality of dyadic relationships or friendships in sport (e.g., Weiss, Smith, \& Theeboom, 1996; Zarbatany, Ghesquire, \& Mohr, 1992) and the role of specific group processes such as peer acceptance, perceived integration in the peer group or perceptions of group cohesion (e.g., Bruner et al., 2014). Interestingly, Denault and Poulin (2007) found no qualitative differences in friendships in terms of duration and support received from friends in and outside sport. Their study also revealed that individual and team sports attract other youths, which resulted in different dyadic relationships (i.e., types of friend) and group dynamics (i.e., integra- 
tion in the peer group). Among other things, they concluded that team sport participants felt more socially integrated, mostly because of age and gender similarities and that their perceptions of social integration were linked to their well-being (e.g., self-esteem). Based on these findings they concluded that more homogenous and cohesive groups in team sport might be a context particularly suited for positive peer interactions and friendship formations. The findings of Denault and Poulin's study (2007) indicated that peer group characteristics that are related to participants' age and gender can positively moderate the relationship between organised sport involvement and selfreported well-being, which may contribute to youth development in this context. Weiss (1998) suggested that a number of other influential characteristics, such as participants' socio-economic status, racial/ethnic background and attitudinal data aggregated on the group-level, could explain why youth may have different outcomes depending on which group they were in. This is in line with Rhodes' (2005) argument that the response of a young person within a social context is, in part, shaped by the ecology of his or her family and surrounding community. For example, susceptibility to peer pressure varies among adolescents exposed to different family structures and parenting styles (Peskins, 1967) and positive peer support is more likely to occur among individuals who share similar characteristics such as ethnicity and education level (Rivera, Soderstrom, \& Uzzi, 2010).

\subsection{Disadvantaged Girls}

We will now focus our attention on disadvantaged girls, primarily for two reasons. First, because research indicates that the participation levels of boys and girls differ greatly, with the latter consistently lower (Green, 2010). Second, because researchers have found low organised sports participation levels among disadvantaged youth in general and girls in particular (e.g., Sabo $\&$ Veliz, 2008). The low participation of disadvantaged girls in sport is of further concern as it has been indicated that involvement in organised sport can be very beneficial for these youth (see Barber, Abbott, Neira, \& Eccles, 2014). Most research on youth in sport has focused on white middle-class populations (Gould et al., 2012). However, studies relating to young people's involvement in youth activities and sport have found that associations between participation and positive indicators are strongest for youth from disadvantaged backgrounds (Marsch \& Kleitman, 2002). For example, Blomfield and Barber (2010) examined the links between developmental experiences, self-conception, and schools' socio-economic status. While the developmental experiences provided to youth in activities, such as sport, were found to positively predict selfworth, social self-conception, and academic self- conception among all youth, these links were much stronger for adolescents from low SES schools.

\section{Study}

In this study conducted in Flanders (the northern, Dutch-speaking part of Belgium), we explore the experiences of disadvantaged girls, a group of youngsters marginalized in the domain of sport. Girls who are underserved in the domain of sport often have a migrant background, are in low educational tracks (i.e., technical/vocational programmes) and grow up in single parent households (Sabo \& Veliz, 2008; Scheerder, Taks, \& Lagae, 2007; Smith, Thurston, Green, \& Lamb, 2007). We also specifically focus on female participants because several researchers found that girls and boys experience sport differently across a number of constructs (e.g., win orientation, parents' belief in their child's sporting abilities, amount of recognition from their fellow team members, coaches, school or community for their athletic accomplishment), which could result in different developmental experiences (Fredricks \& Eccles, 2005; Gould \& Carson, 2011). Despite disadvantaged girls' marginalisation in the domain of sport, researchers assume that this group gains more from their involvement than affluent youth (Blomfield \& Barber, 2010; Marsch \& Kleitman, 2002). However, generalisations about the developmental potential of "sport" are unhelpful because the probability that disadvantaged girls become involved in different types of sport may vary substantially. Activities with a working or lower class image (e.g., soccer, basketball, urban dance, street sports) and activities that are associated with the use of explicit strength (e.g., martial arts and power lifting) (Hellison \& Georgiadis 1992; Janssens \& van Bottenburg 1999; Lagendijk, 1991; Theeboom, De Knop, \& Wylleman, 2008) have been found to be popular for certain youth in vulnerable positions. Full-contact martial arts (e.g., kick boxing, MMA) and urban dance styles (e.g., popping, locking) appeared to be particularly popular in an organised leisure context for girls with disadvantaged backgrounds (e.g., Beaulac, Kristjansson \& Calhoun, 2011; Elling, 2012; Theeboom et al., 2008). The popularity of these types of sport seems to be related to socially vulnerable girls' orientation towards the body and the fact that such activities are valued within these youngsters' subcultures (Elling, 2012; Hellison \& Georgiadis, 1992; Nakeyshaey, 2005). Moreover, disadvantaged girls can participate in different types of sports programmes (Coalter, 2012; Holt, et al., 2011). We refer to the degree to which sports programmes are targeted at disadvantaged girls. In some sports programmes, disadvantaged girls are almost absent or unrecognizable; in contrast, other sports programmes specifically serve these girls. It is interesting to investigate to what extent such intergroup variations have an impact on the 
experiences that disadvantaged girls derive from their participation in sport. Therefore, we (1) assessed what developmental experiences disadvantaged girls report from their participation in sport; (2) examined the relationships between peer group composition and reported experiences among these girls participating in sport; and (3) studied whether these relationships between peer group composition and reported developmental experiences were moderated by the individual characteristics of participants (relating to participants' household structure, educational level and migration background). The following hypotheses are examined based on the earlier research related to (1) the developmental potential of organised sport, (2) the contextual influences within youth sport (i.e., peer groups), and (3) research on the positive impact of organised sport on disadvantaged girls:

- Hypothesis 1: organised sports programmes are settings capable of promoting positive development in girls.

- Hypothesis 2: in sports programmes where there are more similarities between disadvantaged girls, these young people feel more socially integrated are more likely to provide positive peer support and therefore feel less socially isolated, and this may translate into a stronger relationship between a specific target group and positive developmental experiences.

- Hypothesis 3: individual characteristics of disadvantaged girls-migration background, low educational track, non-intact family-will moderate the relationship between group composition and reported developmental experiences. Disadvantaged girls versus affluent girls derive more benefits in a group with a higher percentage of similar peers (in terms of their migration background, low educational level and family structure).

\section{Method}

\subsection{Participants}

A number of specific selection criteria were used to ensure enough disadvantaged girls females in this study. The programmes were selected based on the reported popularity of the sport type for these girls, the specificity of the targeted group and the degree of accessibility. Coaches and coordinators were consulted to gather information about two sampling criteria used to identify those programmes that reach disadvantaged girls (i.e., target group) and the extent to which the programmes specifically serve these girls (i.e., degree of accessibility). A total of 56 sports programmes in Flanders were contacted for this study. The sampling criteria related to the programmes' target groups and their actual degree of accessibility resulted in a selection of
15 sports programmes in Flanders. The selection included six Flemish urban dance programmes and nine full-contact martial arts programmes. Programmes that were not selected for this study did not meet the above-mentioned selection criteria, were not reaching girls, or did not provide the selected types of sport (i.e., full-contact martial arts or urban dance).

The response rate in the present study was very high $(99 \%(202 / 200=0.99))$. The average number of participants within each programme was 14 (ranging between 6 and 27) ( $M=14.3, S D=8.77)$. In the present study, data were collected from 200 female respondents. The sample included 142 (71.00\%) urban dance and $58(29.00 \%)$ martial arts participants. Their age was between 10 and 24 years $(M=15.47$ yrs., SD = 2.15). All respondents attended a minimum of once a week $(M=2.99, \mathrm{SD}=.79)$ and had practiced their sport for at least one year ( $M=2.69$ yrs., $S D=1.21) .51 .4 \%$ of the respondents who were in secondary education $(n=$ 183, 16 primary education, 1 missing) were on a low educational track (i.e., in technical or vocational secondary education). $20.1 \%$ of the respondents that provided information regarding their migration background ( $n=189,11$ missing) were born abroad with most of them of Moroccan, Polish, Turkish or Italian descent. There are several reasons why the authors choose to use nationality and not ethnicity but the main reason was a practical one, namely that several girls (especially the younger ones) were not able to provide the relevant information to take into account their ethnicity (such as the place of birth of their parents, whether or not they belonged to second or third generation). $13.1 \%$ lived in a non-intact family ( $n=199$, 1 missing) (i.e., not with both their biological parents) with the majority (76.9\%) living with their mother. The others were living either with their father $(n=2)$, in an orphanage $(n=2)$, with their grandmother $(n=1)$ or independently under supervision $(n=1)$. Additional descriptive statistics of the sample are displayed in Table 1.

\subsection{Measures}

Two measures were used for this study. A demographic survey was used to collect the independent variables. The "Youth Experience Survey for Sports" (YES-S) (MacDonald et al., 2012) was used to collect the dependent variables. In addition, each questionnaire received a code related to the sports programme in order to facilitate categorisation. The following sociodemographic factors were assessed: age, gender, nationality, educational level and household structure. Nationality was determined based on a child's place of birth and dichotomized and dummy coded into Belgians and participants with a migrant background. Educational levels of the participants were assessed using a 7-point scale ranging from primary to tertiary education (including college and university). 
Table 1. Additional descriptive statistics of the sample $(N=200)$.

\begin{tabular}{|c|c|c|c|}
\hline Variables & & $n$ & $\%$ \\
\hline \multirow{2}{*}{$\begin{array}{l}\text { Migration } \\
\text { background a }\end{array}$} & Belgian & 151 & 79.9 \\
\hline & Born abroad & 38 & 20.1 \\
\hline \multirow{4}{*}{$\begin{array}{l}\text { Secondary } \\
\text { school } \\
\text { programme }^{b}\end{array}$} & Academic $^{d}$ & 89 & 48.6 \\
\hline & Applied & 94 & 51.4 \\
\hline & Technical & 51 & 54.3 \\
\hline & Vocational & 43 & 45.7 \\
\hline \multirow[t]{7}{*}{$\begin{array}{l}\text { Family } \\
\text { structure }^{c}\end{array}$} & $\begin{array}{l}\text { Both biological } \\
\text { parents }\end{array}$ & 173 & 86.9 \\
\hline & Non-intact family & 26 & 13.1 \\
\hline & Mother & 20 & 76.9 \\
\hline & Father & 2 & 7.7 \\
\hline & Grandmother & 1 & 3.8 \\
\hline & Orphanage & 2 & 7.7 \\
\hline & $\begin{array}{l}\text { Independently } \\
\text { under supervision }\end{array}$ & 1 & 3.8 \\
\hline
\end{tabular}

Notes: ${ }^{\mathrm{a}} n=189,11$ missing values; ${ }^{\mathrm{b}} n=183,16$ primary education, 1 missing value; ${ }^{c} n=199,1$ missing value; ${ }^{d}$ "Academic" refers to the general six-year high school programme and is contrasted to the technical and vocational high school programmes, available for high school education in Flanders. In the result section comparisons will be made between two groups including participants within an "academic" and those in an "applied" (i.e., technical/vocational) high school programme.

The 7-point scale consisted of the following response options: (1) Primary or elementary education, (2) General or academic secondary education, (3) Artistic secondary education, (4) Technical secondary education, (5) Vocational secondary education, (6) Higher education (non-university or university), (7) I don't know. Participants were classified into high (i.e., academic) versus low (i.e., applied) educational tracks depending on their secondary school programme. We opted for a dichotomous categorisation wherein we compared students in general or academic education with students in all other tracks or streams together. The data related to this scale was dichotomized and dummy coded into academic secondary education and applied secondary education. Household structure was assessed using a 4-point scale (i.e., both biological parents; one biological parent or alternately by both; a guardian; an orphanage), and the opportunity was provided for participants to mention any other situation in which they lived. This was dummy coded into "intact family" (i.e., with both biological parents) and "nonintact family". The survey also assessed the respondents' frequency of sport involvement; their level of sports experience and their involvement in organised non-sports activities. The intensity was assessed including a 4-point scale ranging from "not every week" to "at least 3 times a week". This was dichotomised and dummy coded into "not every week" and "at least once a week". The level of experience was assessed including a 4-point scale ranging from "less than one year" to "more than five years". This was also dichotomised and dummy coded into "less than one year" and "at least one year". Participation in organised non-sports activities during leisure time was assessed using four categories. These categories of organised non-sports activities were based on existing research (e.g., Hansen \& Larson, 2007; Larson et al., 2006) and included: performance and fine arts (drama, band), academic activities (tutoring, chess club, debate club), faith-based and service activities (volunteering), and community and vocational clubs (Scouts). If a specific activity was not listed in a category, the participant could type in the name of the activity.

YES-S was constructed to assess the positive and negative developmental experiences occurring in the domain of sport. It is comprised of five scales (including four positive scales and one negative one) and 37 items that fall within these scales. These include: (1) personal and social skills (e.g., "I became better at giving feedback"); (2) cognitive skills (e.g., "This activity increased my desire to stay in school"), (3) goal setting (e.g., "I observed how others solved problems and learned from them"), (4) initiative (e.g., "I learned to focus my attention"); (5) and negative experiences (e.g., "I was treated differently because of my gender, race, ethnicity, disability, or sexual orientation"). For each item, participants used a four-point Likert-type scale ranging from 1 ("not at all") to 4 ("yes, definitely") to describe the extent to which they felt a given experience is characteristic of their involvement in sport. Since no validated Dutch version exists of the YES-S, a forward and back translation method was used. It was translated from English to Dutch by bilingual Dutch and English speakers, retranslated and modified by the researchers if necessary.

\subsection{Procedures}

Coach(es) and/or youth worker(s) from each sports programme provided assistance for organising the survey, but were not present during the actual completion. Before administrating the survey, parents and coaches were informed about the purpose of the study. Respondents were informed about the purpose of the study, that participation was voluntary and that their information would not be shared with members of the coaching staff or parents. During adminstration researchers provided assistance to help complete the survey (i.e., explained the Likert-scale, etc.) and ensured that each participant completed her questionnaire without being influenced by her peers. Some items were formulated in a simplified way (in italics under the original question) or provided with additional information. The selection of these items was based on a preliminary study involving eight young adoles- 
cents (aged between 10-12 years) from different socioeconomic backgrounds. On average, the administration took between 20 to 30 minutes.

\subsection{Data Analysis}

To account for the hierarchical data structure (participants clustered within sports clubs), multilevel regression analyses were performed using MLwiN 2.30. This software package is specifically designed to conduct multi-level analysis and is used in various research domains (e.g., education sciences). For the outcomes "personal and social skills", "cognitive skills", "goal setting" and "initiative", multilevel linear regression analyses were performed (Steele, 2008). A stepwise approach was followed to construct a final model. First, three separate models were constructed including the individual- and group-level variable of one of the three indicators of a girl's disadvantaged background and their interaction effect. Second, those main and interaction effects that proved to be significant in the first step, were entered into one combined model. Third, this model was simplified by deleting the nonsignificant effects that did not improve the model fit (based on the likelihood ratio test). The significance of individual parameters was tested by $\mathrm{Chi}^{2}$-tests. Since the outcome "negative experiences" was heavily positively skewed, this variable was dichotomised around its median (=1.20). Values equal to or lower than the median were coded " 1 " (no negative experiences) and values above the median were coded " 0 " (negative experiences). Multilevel logistic regression analyses were performed to analyse the odds of having reported no negative experiences. The same stepwise approach as described above was followed to construct the final model. Parameter estimates were obtained via Markov Chain Monte Carlo (MCMC) procedures (burn-in length $=50,000$ and monitoring chain length $=200,000$ ) (Browne, 2012). To facilitate interpretation, significant interaction effects were illustrated using MLwiN's customized prediction function (Rasbash, Charlton, Jones, \& Pillinger, 2009). All analyses were adjusted for the participants' ages and types of sport. Since the level of involvement in sport appeared to be related to "initiative" experiences during exploratory analyses, all analyses for "initiative" were adjusted for the level of sport involvement. The frequency of sport involvement and involvement in organised non-sports activities were not related to any of the YES-S dimensions, and therefore they were not included in any of the models. The level of significance was determined at 0.05 . To estimate the local effect size of significant relationships, the proportional reduction in variance statistic (PRV) was calculated for the explained variance at the participant and team levels and for the total variance (Peugh, 2010). The PRV represents the reduction in variance in the dependent variable attributable to the inclusion of the corresponding independent variable. The percentage of explained variance by the total model was also calculated. It should be noted that the percentage of variance explained by the total model can be smaller than the sum of the explained variances of the predictors (Peugh, 2010). When a significant interaction effect was present, PRV was calculated for the inclusion of the two main effects and the interaction effect.

\section{Results}

\subsection{Reliability and Descriptive Statistics}

Reliability estimates (i.e., Cronbach alpha values) are displayed between brackets in Table 2. Based on previous research conducted with youths, values of .60 and higher were considered to be adequate (Wilkes \& Côté, 2010). Data collected for the present study demonstrated that the YES-S had acceptable to high internal consistency measured by Cronbach's Alpha (.66-.85). Secondly, Table 2 provides the descriptive statistics for the dependent variables. Considering that the YES-S used a 4-point Likert scale, ratings for positive experiences were relatively high (Total $M=2.90$ ), and ratings for negative experiences were low $(M=1.31)$. The highest positive subscale scores were found for initiative $(M=3.37)$, followed by personal and social skills $(M=2.90)$, goal setting $(M=2.70)$ and cognitive skills $(M=2.14)$.

Table 2. Descriptive statistics for dependent variables (means with standard deviations and reliability values between brackets) $(N=200)$

\begin{tabular}{lc}
\hline Dependent variables & Total \\
\hline YES-S Positive experiences [.852] $M(S D)$ & $2.90(.45)$ \\
Personal and social skills [.790] $M(S D)$ & $2.90(.46)$ \\
Cognitive skills [.724] $M(S D)$ & $2.14(.71)$ \\
Goal setting [.746] $M(S D)$ & $2.70(.68)$ \\
Initiative [.667] $M(S D)$ & $3.37(.54)$ \\
YES-S Negative experiences [.846] $M(S D)$ & $1.31(.43)$ \\
\hline
\end{tabular}

\subsection{Relationships between Developmental Experiences and Group Composition}

Table 3 summarizes the results of the multilevel regression analysis ${ }^{1}$.

\footnotetext{
${ }^{1}$ Multilevel modelling takes into account the different levels in a hierarchical sample (i.e., group and participant level), by separating the variance attributable to these different levels. This technique was used to explore the relationship between the group composition and participants' reported experiences.
} 


\section{COGITATIO}

Table 3. Results of the regression model predicting positive developmental experiences.

\begin{tabular}{|c|c|c|c|c|c|c|c|c|c|c|c|c|c|}
\hline \multirow{2}{*}{$\begin{array}{l}\text { Positive YES-S } \\
\text { Subscales }\end{array}$} & \multirow{2}{*}{ Significant predictors and moderators } & \multirow{2}{*}{$b(S E)$} & \multirow{2}{*}{$p$} & \multicolumn{2}{|c|}{$\begin{array}{c}\text { \% Variance explained by } \\
\text { null model }\end{array}$} & \multicolumn{3}{|c|}{$\begin{array}{l}\text { \% Variance explained by } \\
\text { predictor }\end{array}$} & \multicolumn{2}{|c|}{ Variances in final model ${ }^{1}$} & \multicolumn{3}{|c|}{$\begin{array}{c}\text { \% Variance explained by } \\
\text { final model }\end{array}$} \\
\hline & & & & $\begin{array}{c}\text { Participant } \\
\text { level }\end{array}$ & $\begin{array}{l}\text { Team } \\
\text { level }\end{array}$ & $\begin{array}{c}\text { Participant } \\
\text { level }\end{array}$ & $\begin{array}{l}\text { Team } \\
\text { level }\end{array}$ & Total & $\begin{array}{l}\text { Participant level } \\
\quad \sigma 2(S E)\end{array}$ & $\begin{array}{c}\text { Team level } \\
\sigma 2(S E)\end{array}$ & $\begin{array}{c}\text { Participant } \\
\text { level }\end{array}$ & $\begin{array}{l}\text { Team } \\
\text { level }\end{array}$ & Total \\
\hline \multirow[t]{6}{*}{ Goal Setting } & Intercept & $2.654(0.109)$ & & 94.7 & 5.3 & & & & $0.372(0.040)$ & $0.002(0.010)$ & 16.0 & 92.0 & 20.1 \\
\hline & Group-level secondary education & $0.007(0.002)$ & $0.007^{*}$ & & & 2.1 & 80.0 & 4.1 & & & & & \\
\hline & Individual secondary Education (ref = academic) & $-0.095(0.106)$ & 0.37 & & & & & & & & & & \\
\hline & Group-level family structure & $-0.013(0.004)$ & $0.001 *$ & & & 12.3 & 80.0 & 13.8 & & & & & \\
\hline & Individual family structure (ref = intact family) & $-0.816(0.298)$ & 0.006 & & & & & & & & & & \\
\hline & Group-level * Individual family structure & $0.059(0.013)$ & $0.001 *$ & & & & & & & & & & \\
\hline \multirow{6}{*}{$\begin{array}{l}\text { Personal and Social } \\
\text { Skills }\end{array}$} & Intercept & $2.618(0.122)$ & & 91.9 & 8.1 & & & & $0.173(0.019)$ & $0.007(0.008)$ & 10.8 & 58.8 & 14.6 \\
\hline & Group-level secondary education & $0.004(0.002)$ & $0.04 *$ & & & 0.0 & 46.2 & 3.2 & & & & & \\
\hline & Individual secondary education (ref = academic) & $-0.052(0.072)$ & 0.47 & & & & & & & & & & \\
\hline & Group-level family structure & $-0.004(0.003)$ & 0.20 & & & 6.0 & 0.0 & 5.3 & & & & & \\
\hline & Individual family structure (ref = intact family) & $-0.426(0.207)$ & 0.04 & & & & & & & & & & \\
\hline & Group-level * Individual family structure & $0.028(0.009)$ & $0.002 *$ & & & & & & & & & & \\
\hline \multirow[t]{5}{*}{ Cognitive Skills } & Intercept & $1.865(0.115)$ & & 85.4 & 14.6 & & & & $0.357(0.038)$ & $0.000(0.000)$ & 18.3 & 100.0 & 30.3 \\
\hline & Group-level secondary education & $0.007(0.002)$ & $0.001 *$ & & & 4.8 & 100.0 & 5.8 & & & & & \\
\hline & Individual secondary Education (ref = academic) & $-0.106(0.107)$ & 0.32 & & & & & & & & & & \\
\hline & Group-level nationality & $0.006(0.003)$ & $0.04 *$ & & & 1.9 & 100.0 & 2.5 & & & & & \\
\hline & Individual nationality (ref = Belgian) & $0.191(0.132)$ & 0.15 & & & & & & & & & & \\
\hline \multirow[t]{4}{*}{ Initiative } & Intercept & $3.331(0.098)$ & & 94.3 & 5.7 & & & & $0.246(0.026)$ & $0.004(0.008)$ & 11.5 & 76.5 & 15.3 \\
\hline & Group-level family structure & $-0.005(0.003)$ & 0.14 & & & 2.0 & 42.8 & 3.1 & & & & & \\
\hline & Individual family structure (ref = intact family) & $-0.269(0.246)$ & 0.27 & & & & & & & & & & \\
\hline & Group-level * Individual family structure & $0.021(0.010)$ & $0.04 *$ & & & & & & & & & & \\
\hline
\end{tabular}


For goal setting, a small proportion of the variance (5.3\%) appeared to be related to the team level. The remaining $94.7 \%$ of the total variance regarding goal setting experiences could be attributed to differences between participants. We found a significant main effect for group-level educational track. The percentage of team members from a low educational track was significantly positively related to goal setting; an increase of $1 \%$ in the percentage of team members from a low educational track was related to an increase in goal setting by 0.007 (SE $=0.002, p=0.007$ ) on a 4-point Likert scale. In addition, the analysis revealed a significant interaction effect $(b=0.059, S E=0.013, p=0.001)$ between the participant's and group-level family structure. This implies that the relationships between grouplevel family structure and goal setting differed according to participant's family structure (see Figure 1).

Among participants that lived in non-intact families, goal setting significantly increased with an increasing proportion of team members living in non-intact families. An increase in the percentage of participants in a team living in non-intact families of $1 \%$ was related to an increase in goal setting of 0.046 (SE $=0.012$, $p<0.001$ ) on a 4-point Likert scale. The opposite was observed for participants that lived in intact families. Among participants that lived in intact families, goal setting significantly decreased with an increasing proportion of team member living in non-intact families. An increase in the percentage of participants in a team living in non-intact families of $1 \%$ was related to a decrease in goal setting of 0.013 (SE $=0.004, p=0.001$ ) on a 4-point Likert scale. Our model highlights that $80.0 \%$ of the variance at the group level and $12.3 \%$ of the variance at the individual level was explained by the interaction between the family structure on both the participant level and the team level. The overall model for goal setting explained $92.0 \%$ of the variance at the group level and $16.0 \%$ of the variance at the individual level. Overall, $20.1 \%$ of the variance in goal setting was explained.

For personal and social skills, $8.1 \%$ of the variance appeared to be explained by the team level. The analysis showed a significant positive relationship between the percentage of team members in a low educational track and personal and social skills. The analysis also revealed a significant interaction effect $(b=0.028, S E=$ $0.009, p=0.002$ ) between the respondent's family structure at both the participant and team levels (Figure 2).

Among participants that lived in non-intact families, an increase of $1 \%$ in the proportion of participants in a team living in non-intact families was related to an increase in personal and social skills of 0.024 ( $S E=0.009$, $p=0.007$ ) on a 4-point Likert scale. Among participants that lived in an intact family, no significant relationship ( $b=-0.004, S E=0.003, p=0.20$ ) was found between the amount of participants in a team that lived in nonintact families and personal and social skills. Our model highlights that none of the variance $(0.0 \%)$ at the group level and $6.0 \%$ of the variance at the individual level is explained by the interaction between the family structure on both the participant level and team level. The overall model explained $58.8 \%$ of the variance at the group level and $10.8 \%$ of the variance at the individual level. Overall, $14.7 \%$ of the variance in personal and social skills was explained.

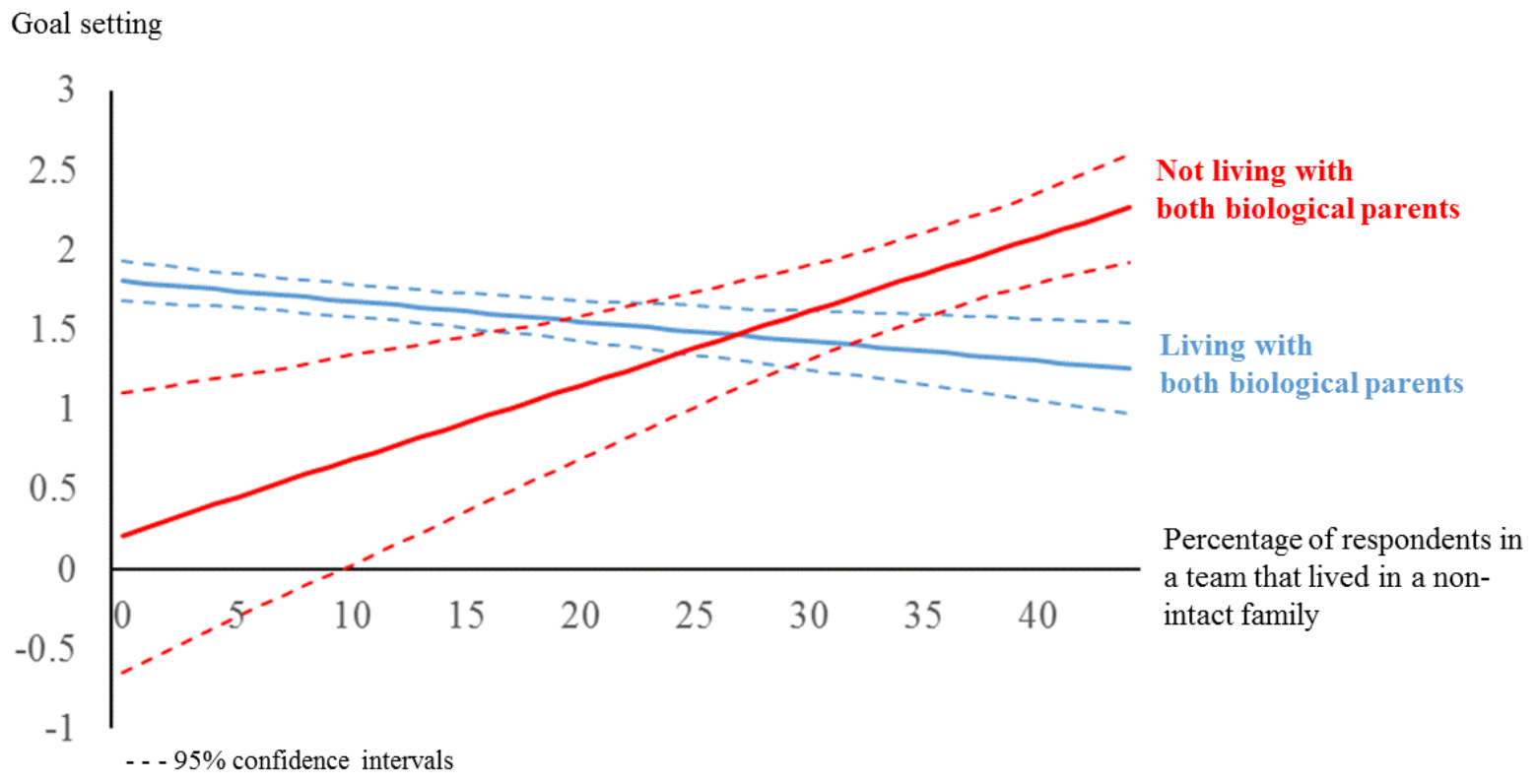

Figure 1. Interaction effect for goal setting between the respondents' family structures on the participant and team levels. 
For cognitive skills, $14.6 \%$ of the variance was explained by the team level. A significant positive relationship between the amount of participants on a low educational track and cognitive skills was observed. Another significant positive association was observed between the percentage of team members with a migrant background and cognitive skills. The overall model for cognitive skills explained $100.0 \%$ of the variance at the group level and
$18.3 \%$ of the variance at the individual level. Overall, $30.3 \%$ of the variance in cognitive skills was explained.

For initiative, $5.7 \%$ of the variance was explained by the team level. No significant main effects for group level predictors were found. However, the analysis revealed a significant interaction effect $(b=0.021, S E=0.010, p=$ 0.04 ) between the respondents' family structures at the participant level and at the team level (see Figure 3).

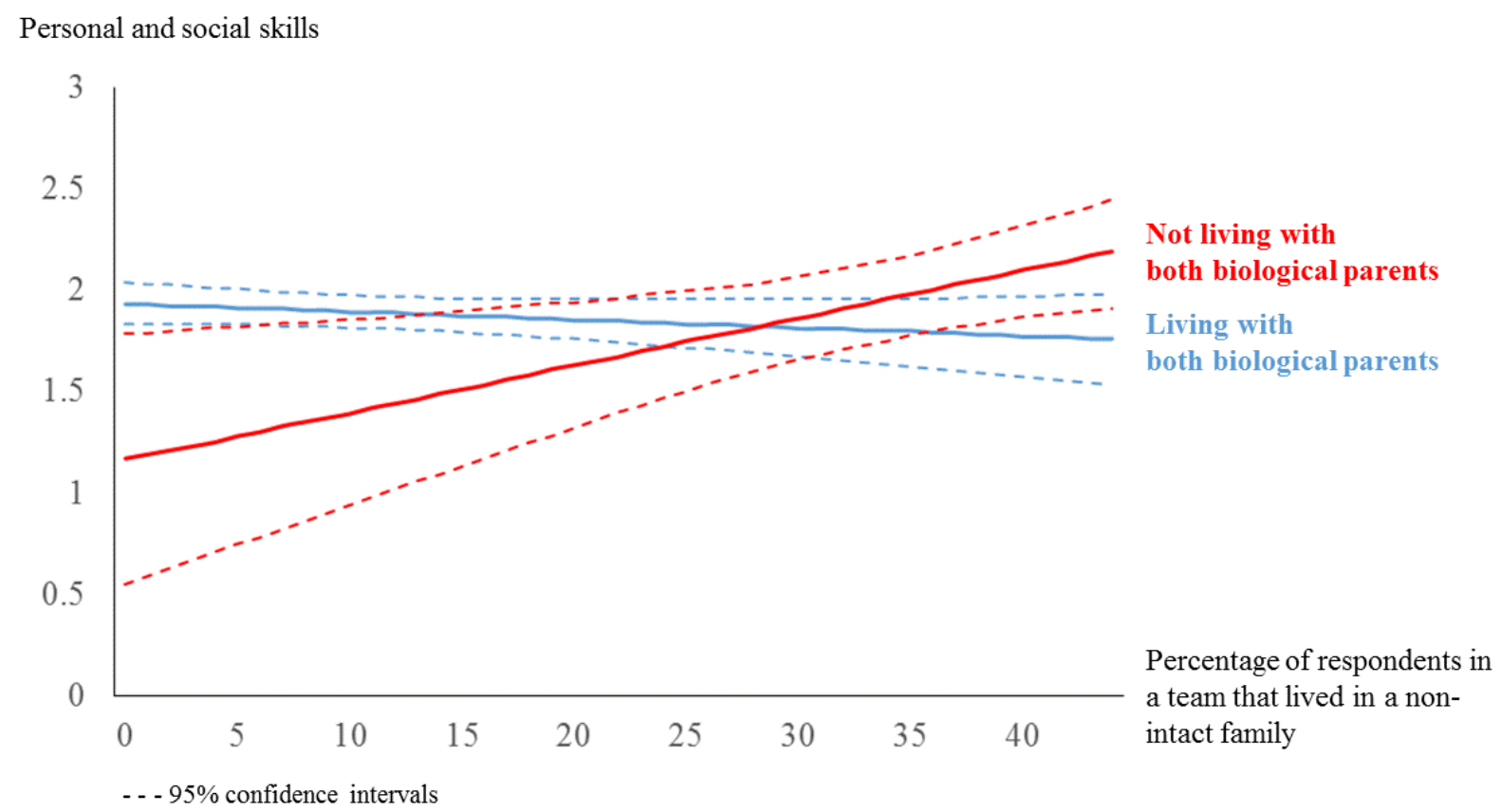

Figure 2. Interaction effect for personal and social skills between the respondents' family structures on the participant level and team level.

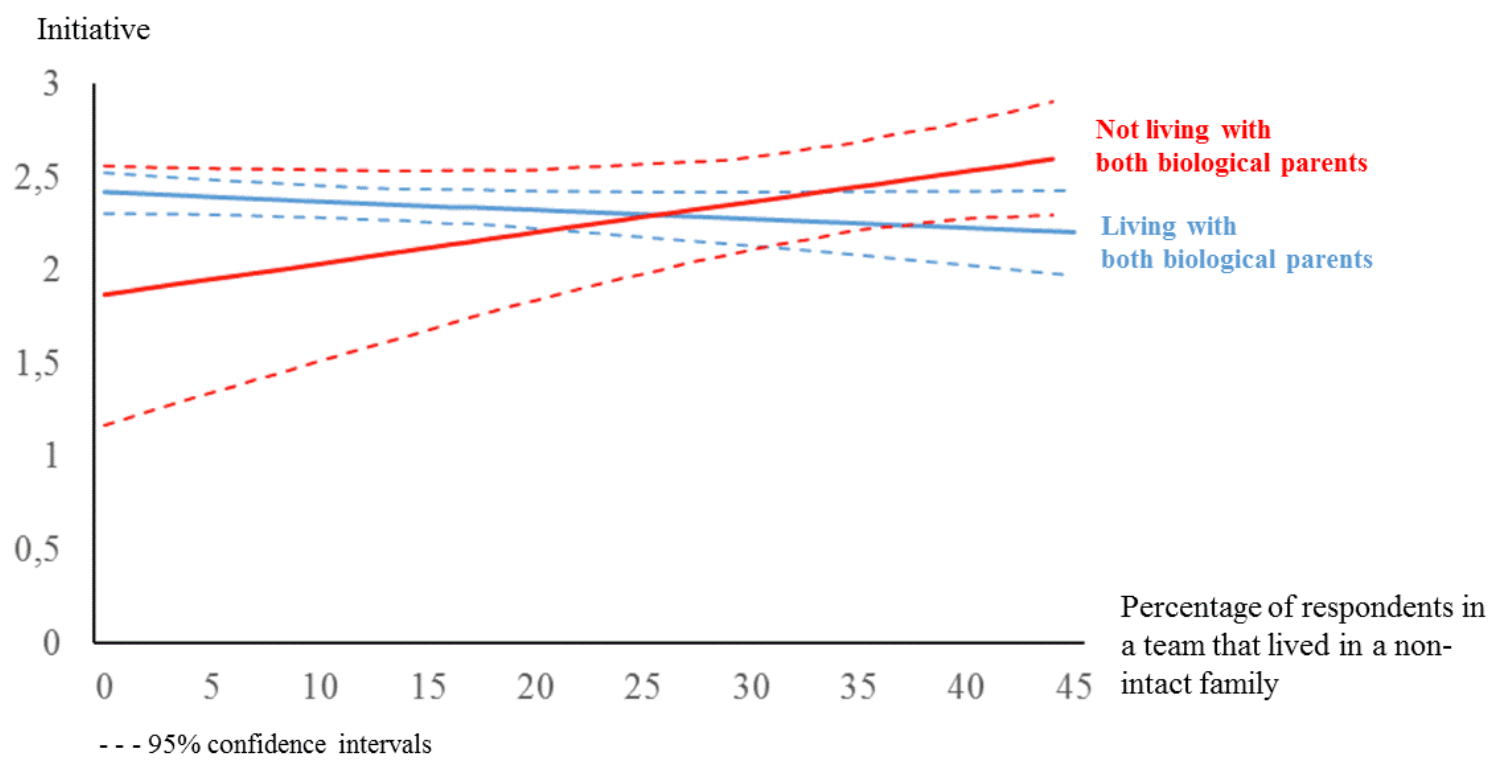

Figure 3. Interaction effect for initiative between the respondents' family structures on the participant level and team level. 
Among participants that lived in a non-intact family, an increase in the percentage of group participants living in non-intact families of $1 \%$ was related to an increase in initiative of 0.016 (SE $=0.010, p=0.04$ ) on a 4-point Likert scale. Among participants that lived in an intact family, no significant relationship was found between the amount of participants in a team that lived in nonintact families and initiative $(b=-0.005, S E=0.003, p=$ 0.14). Our model highlights that $42.8 \%$ of the variance at the group-level and $2.0 \%$ of the variance at the individual level could be explained by the interaction between the household structure on the participant level and the team level. The overall model explained $76.5 \%$ of the variance at the group level and $11.5 \%$ of the variance at the individual level. Overall, $15.3 \%$ of the variance was explained.

For the model related to negative experiences, no significant main effects of the group level predictors nor significant interaction effects were found.

\section{Discussion}

In this study conducted in Flanders, we looked at disadvantaged girls. As mentioned earlier, these girls often have a migrant background, are in low educational tracks (i.e., technical/vocational programmes) and grow up in single parent households (Sabo \& Veliz, 2008; Scheerder, Taks, \& Lagae, 2007; Smith, Thurston, Green, \& Lamb, 2007). These three personal characteristics were included as separate variables in this study and provided specific insights regarding disadvantaged girls' reported gains in organised sport. This study was designed to assess what developmental experiences disadvantaged girls report from their participation in sport and to measure the relationships between disadvantaged girls' reported gains and the composition of their activity peer group. It was also set up to investigate whether these relationships between group composition and reported developmental experiences were moderated by participants' individual characteristics (i.e., participants' family structures, educational levels and migration backgrounds).

According to Fraser-Thomas and colleagues (2005), there are different paths to positive youth development through sport, and youth may experience group environments differently even though they are engaged in the same sport context. Qualitative research in the domain of PYD supports this as well (e.g., Riley \& Anderson-Butcher, 2012). Our results suggest that the relationship between group composition and reported developmental experiences is moderated by the individual's family structure. Findings related to the goal setting domain show that both girls from non-intact and intact families derive more benefits in a group with more participants with a similar family structure. With Ryan and Deci's self-determination theory (2000) in mind, we could suggest that family structure is one of the individual characteristics that maintains and reinforces belonging among peers. According to their theory, a sense of belonging is one of the fundamental psychological needs (along with autonomy and perceived competence) to initiate an individual's innate tendencies towards development. Our findings also concur with Deci and Ryan's (2000) claim that all three psychological needs are essential, but that the degree to which they are fulfilled varies from one context to another. The results of the present study seem to suggest that feelings of belonging for girls are most likely to be realised through having things in common (such as a similar family structure). It appears that this interconnection in the group environment facilitates a more positive learning environment. Research in after-school programmes and community sport also underlines the value of belonging for promoting positive developmental outcomes (e.g., Ullrich-French \& Smith, 2009). Researchers have suggested that young people who feel they belong to learning environments report higher enjoyment, interest, happiness, enthusiasm, and more confidence in engaging in learning activities, whereas those who feel isolated report greater frustration, anxiety, sadness, and boredom during academic engagement, which affects their performance (Furrer \& Skinner, 2003). However, we should also mention that no relationship was found in two cases for girls from intact families (i.e., personal and social skills, initiative). It could perhaps be that other psychological needs of the self-determination theory (i.e., autonomy or perceived competence) have more influence in facilitating such developmental experiences among girls from intact families. It is also important to mention that our findings related to the interaction effects suggest that girls from non-intact families in a group of peers with a similar family situation will still derive more benefits than girls from intact families in a group of similar peers. These findings confirm, in part, our third hypothesis and indicate that researchers investigating the relationship between sports participation and PYD should take into account characteristics at the individual level and the group level, as well as the interaction between both levels in order to understand if some girls derive more benefits than others from their participation in organised sport. Similar to other empirical research (e.g., Blomfield \& Barber, 2010), our findings related to interaction effects have shown that disadvantaged youth gains more than affluent youth from their participation in organised activities (such as sport).

Next to the findings related to participants' family structure, we also have some interesting results related to girls from a low educational track or with a migrant background. The results of our study showed, for example, a significant positive relationship between the percentage of team members in a low educational track and personal and social skills. Similar results were found for cognitive skills and goal setting. These find- 
ings partially confirm our second hypothesis because we found significant relationships for only two variables (i.e., participants' educational levels and migration backgrounds). But what might explain these significant positive relationships? One possible explanation is that the more homogenous groups (in terms of low educational track and migration background) could have reported more developmental experiences as a result of a more positive peer sports climate that is facilitated by a specific coaching climate implemented in these programmes. This could, perhaps, imply that programmes that reach heterogeneous groups could facilitate as much PYD in these domains by implementing a similar coaching climate.

Heterogeneous and homogeneous activity peer groups are related to mixed and separate sports clubs. We should, therefore, also point to research related to the social capital theory on bonding and bridging processes in mixed and separate sports clubs. For example, Theeboom and his colleagues (2012) investigated the development of social capital among ethnic minorities in mixed and separate sports clubs. These investigators highlighted that mixed sports club members indicated more that they learned to make contact with others, became self-confident and learned about other ethnic groups, while members of separate sports clubs appeared to have more personal non-sports-related conversations with other members and helped each other more often outside the sporting context. Based on such findings researchers concluded that separate sports clubs are not necessarily more beneficial for participants' development than mixed sports clubs (Theeboom, Schaillée, \& Nols, 2012; Verweel et al., 2005).

Another finding of this study is that respondents did not have many negative experiences. This is an important finding, particularly for disadvantaged girls, as it is known from a large body of research that negative experiences can contribute to negative stress; and that youths who experience multiple simultaneous stressors are more likely to become depressed, use substances, engage in risky sexual activity or manifest other problems (e.g., Chassin et al., 2004). It has been reported that, compared to other youngsters, disadvantaged youth is often characterised by more negative experiences in their institutional contacts (Vettenburg \& Walgrave, 2009). For example, youths with a migrant background skip school more often (Vogels \& Bronneman-Helmers, 2000), have lower academic scores and are seven times more likely to end up on a low educational track compared to other students (Stevens, De Groof, \& Burssens, 2006). Similarly, youths on lower educational tracks appear to have lower perceptions of school membership (Smerdon, 2002) and a lower sense of belonging in class (Van Houtte \& Maele, 2012) compared to those in higher educational tracks. Several of the above-mentioned studies suggest commonalities among youth in disadvantaged situations (e.g., regarding educational tracks). We need, however, to be cautious with regard to over-generalisation (e.g., with regard to migration background and to youths' experiences of and reaction to institutional contacts). Although homogeneous groups within sports programmes might be very similar to the homogeneous student populations in vocational schools (i.e., lowerclass students and students from ethnic minority groups), there are several reasons not to expect similar influences. For example, sport is a leisure activity implying voluntary engagement. There is often an interest to look for similar cultural capital among peers and coaching staff. For example, Ramsahai (2008) referred to the need to first construct a strong (ethnic) identity before building up sustainable relationships with other minority or majority groups.

The YES-S means and standard deviations show that the girls involved in this study perceived initiative, personal and social skills, and goal setting as the benefits they most often derived from their participation in sport. The hypothesis that sports participation can facilitate developmental experiences independently of girls' disadvantaged background could therefore be confirmed. These results compare favourably with Gould et al.'s study (2012), which showed that the positive experiences of teamwork and social skills, physical skill development and initiative were most experienced by underserved youth sports participants. Though the instruments used in both studies are theoretically different, it has been indicated that the YES-S and YES 2.0 share similarities (MacDonald et al., 2012). The YES-S factors consist of YES 2.0 items related to the concepts of "initiative", "positive peer relationships", "adult network and social capital", and "teamwork and social skills" outlined by Hansen and Larson (2005). The initiative subscale of the YES-S is based on the notion of initiative, as described by Larson (2000). He argued that initiative will develop in youth who are intrinsically motivated by the activity, who invest high amounts of attention and effort, and participate in an activity for a significant amount of time. The other two factors of the YES-S may prove to be very valuable because experiences in these domains of learning (e.g., receiving feedback) could also have positive effects in other facets of young people's lives (Danish, Fazio, Nellen, \& Owen, 2002; Gould et al., 2012). There is, however, a broad consensus among sports psychologists that life skills, defined as the skills that are required to deal with the demands and challenges of everyday life (Hodge \& Danish, 1999), are not necessarily transferred into other social settings. Danish, Petitpas and Hale (1990) argued that the sports experience should be designed is such a way that participants can transfer what is learned into other domains such as school, home, and/or a workplace. They suggested that in order to facilitate such a transfer, it is necessary to help participants in recognising the skills that they have acquired 
through sport and to clarify the use of these skills in other life domains. A variety of skills such as effective communication with peers and adults or effective decision-making can be learned in a sport context and transferred into other life domains. According to Gould and Carson (2008), coaches play and influential role in the process of coaching life skills through sport and developed a five-component model for understanding this process. Their model emerged from an extensive review of the literature on positive youth development through extracurricular activities and sport and could be used to evaluate sports programmes' efficacy regarding life skills transfer.

Like all studies, this study has several limitations that must be considered. First, we looked at girls involved in urban dance or martial arts programmes. Although we controlled for the type of sport, this could mean that these two different sports offer distinct social contexts and opportunities for socialisation. For example, a martial arts participant may spend a greater amount of one-on-one quality time with a peer than an urban dance participant. On the other hand, the broader social system of an urban dance team may provide learning experiences that are not available in a dual sports activity such as martial art. Second, taking into account that we wanted to investigate the influence of group composition, it was essential to include all participants. This resulted in substantial age differences in our population (i.e., 14 years). Although we controlled for this variable, it does not rule out that the experiences of a 10 year-old from participating are probably different from those of a 24 year-old in the same group. Several studies showed that over the course of their development, adolescents report to be less susceptible to peer influence in general (e.g., Sumter, Bokhorst, Steinberg, \& Westenberg, 2009). This suggests that over time adolescents gain more autonomy from their peers as a result of increasing psychosocial maturity. Third, although self-reporting has been regarded as a good method to assess youth experiences in sports activities, this methodology also has limitations such as response bias (e.g., social desirability, inaccurate memory). Fourth, our findings are based on correlational data at a single point in time, and do not allow for conclusions of direction or cause. The relevant causal relationships can be further explored by using, for example, longitudinal data. Future studies could investigate the relative importance of different contextual variables (e.g., type of sport) by exploring the extent to which each factor can have an effect on reported experiences.

\section{Conclusions}

The point of departure of this study has been the relevance of group composition for the experiences that disadvantaged girls derive from their participation in sport. We perceived this as a relevant question because it has been suggested that preference should be given to contextual factors that can be changed or manipulated, rather than fixed attributes over which programmes have little control (Weiss, 1998). There is some research evidence indicating that the contextual variable (i.e., peer group) studied here can be changed through specific recruitment strategies and by changing the location where the activities take place (e.g., Schaillée \& Theeboom, 2014). Findings of the present study suggest that the peer group composition in organised sport can contribute to girls' experiences, but how they matter can only be fully understood in the contexts of the participants' lives in combination with the characteristics of their fellow team members. Investigating the moderating effect of participants' disadvantaged backgrounds in facilitating PYD is a relevant topic as it would provide more insights into effective coaching and organisational strategies to be used to create supportive and rich learning environments for young people. As communities and organised sports programmes are very diverse, gaining such deeper understanding is essential. According to Armour (2011), coaches or those working with young people, need to continuously critically examine the ways sports activities are provided in terms of creating positive and valuable experiences for youths. More research is however needed that specifically focuses on the value and meaning disadvantaged girls give to specific and varied forms of participation in sport.

The findings reported in this paper are based on 10-24 year-old girls' perceived experiences. But there are several important questions that remain unanswered. For instance, we have not investigated whether the developmental experiences in a same-group environment differ according to the ages of the participants. Nor do we know whether there are certain developmental experiences that are more prevalent at a given developmental stage (e.g., older adolescents). It should also be recognised that the group composition examined here only represents a small subset of the programme level variables that are likely to affect youth developmental experiences. The statistical models of our study show that about $14.6-30.3 \%$ of the experiences in the different developmental domains are linked to the group composition; thus the majority of these positive experiences have to be explained by other contextual factors. The group composition is likely to be part of a complex web working with other contextual factors in leading to positive youth development in a sports context. Other important factors are, for example, the young person's motivation (Hansen \& Larson, 2007) and the perceived relationships between the athletes and their coaches (Petitpas et al., 2005). However, differences relating to perceived cognitive skill experiences at the team level cannot be further explained by other contextual fac- 
tors, while such differences for other domains of learning (e.g., personal and social skills) can still, at least in part, be explained by other aspects which may differ at the team level (e.g., motivational coaching approach). The multilevel approach used in this study permitted a simultaneous examination of the influence of individual characteristics on girls' PYD at individual and group levels. With variability in PYD at both the individual and team levels, future research should not overlook the impact of the interdependent nature and influence of the social context of sports programmes on PYD. But despite this variability, the results of this study clearly suggest that organised sports programmes can be an important context for promoting positive youth development among disadvantaged girls.

\section{Conflict of Interests}

The authors declare no conflict of interests.

\section{References}

Armour, K. (2011). Sport pedagogy: An introduction for teaching and coaching. New York: Routledge.

Barber, B., Abbott, B., Neira, C., \& Eccles, J. (2014). Meaningful Activity Participation and Positive Youth Development. In M. J. Furlong, R. Gilman, \& E. S. Huebner (Eds.), Handbook of positive psychology in schools (pp. 227-244). New York: Routledge.

Beaulac, J., Kristjansson, E., \& Calboun. M. (2011). 'Bigger that Hip-Hop?' Impact of community-based physical activity program on youth living in a disadvantaged neigborhood in Canada. Journal of Youth Studies, 14(8), 961-974.

Blomfield, C., \& Barber, B. L. (2010). Australian adolescent's extracurricular activity participation and positive development: Is the relationship mediated by peers?. Australian Journal of Educational Developmental Psychology, 10, 108-122.

Bronfenbrenner, U. (1999). Environments in developmental perspective: Theoretical and operational models. In S. L. Friedman, \& T. D. Wachs (Eds.), Measuring environment across the life span (pp. 328). Washington, DC: American Psychological Association.

Browne, W. (2012). MCMC Estimation in MLwiN version 2.25. Centre for Multilevel Modelling. University of Bristol. Retrieved from http://www.bristol.ac.uk/ $\mathrm{cmm} /$ software/mlwin/download/mcmc-print.pdf

Bruner, M. W., Eys, M. A., Wilson, K. S., \& Côté, J. (2014). Group cohesion and positive youth development in team sport athletes. Sport, Exercise, and Performance Psychology, 3(4), 219-227.

Catalano, R. F., Berglund., L. M., Ryan, J. A. M., Lonczak, H. S., \& Hawkins, J. D. (2004). Positive youth development in the United States: Research findings on evaluations of positive youth development pro- grams. The ANNALS of the American Academy of Political and Social Science, 594(1), 98-124.

Chassin, L., Husson, A., Barrera, M., Molina, B., Tim, R. \& Ritter, J. (2004). Adolescent substance use. In R. Lerner \& L. Steinberg (Eds.), Handbook of adolescent psychology (pp. 665-696). Hoboken, NJ: Wiley.

Coalter, F. (2012). 'There is loads of relationships here': Developing a programme theory for sport-for change programmes. International review for the sociology of sport, $0(0), 1-19$.

Danish, S. J., Fazio, R. J., Nellen, V. C., \& Owen, S. S. (2002). Teaching life skills through sport: community-based programs to enhance adolescent development. In J. L. Van Raalte, \& B. W. Brewer (Eds.), Exploring sport and exercise psychology (2nd ed., pp. 269-288). Washington, DC: APA.

Danish, S., Petitpas, A., \& Hale, B. (1990). Sport as a context for developing competence. In T. Gullotta, G. Adams, \& R. Monteymar (Eds.), Developing social competency in adolescence (Vol. 3, pp. 169-194). Newbury Park, CA: Sage.

Deci, E.L., \& Ryan, R.M. (2000). The 'what' and 'why' of goal pursuits: Human needs and the selfdetermination of behavior. Psychological Inquiry, 11(4), 227-268.

Denault, A-S., \& Poulin, F. (2007). Sports as peer socialization contexts. International Journal of Behavioural Development, 31(52), 5-7.

Dworkin, J. B., Larson, R., \& Hansen, D. (2003). Adolescents' accounts of growth experiences in youth activities. Journal of Youth and Adolescence, 32, 17-26.

Eccles, J., \& Gootman, J. A. (2002). Community programs to promote youth development/Committee on community-level programs for youth. Washington, DC: National Academies Press.

Elling, A. (2012). Sport: ook een vrouwenzaak [Sport: also a women's thing]. Raffia, 3, 3-6.

Fraser-Thomas, J.L., Côté, J. (2009). Understanding adolescents' positive and negative developmental experiences in sport. The Sport Psychologist, 23, 3-23.

Fraser-Thomas, J. L., Côté, J. and Deakin, J. (2005). Youth sport programs: an avenue to foster positive youth development. Physical Education and Sport Pedagogy, 10(1), 19-40.

Fredricks, J. A., \& Eccles, J. S. (2005). Extracurricular involvement and adolescent adjustment: Impact of duration, number if activities, and breadth of participation. Applied Developmental Science, 10(3), 132-146.

Furrer, C., \& Skinner, E. (2003). Sense of relatedness as a factor in children's academic engagement and performance. Journal of Educational Psychology, 95, 148-162.

Garcia Bengoechea, E., \& Johnson, G. M. (2001). Ecological systems theory and children's development in sport: Toward a process-person-context-time research paradigm. Avante, 7, 20-31. 
Gould, D., \& Carson, S. (2008). Life skills development through sport: Current status and future directions. International Review of Sport \& Exercise Psychology, 1, 58-78.

Gould, D., \& Carson, S. (2011). Young athletes' perceptions of the relationship between coaching behaviors and developmental experiences. International Journal of Coaching Science, 5(2), 3-29.

Gould, D., Flett, R., \& Lauer, L. (2012). The relationship between psychosocial developmental and the sports climate experienced by underserved youth. Psychology of Sport and Exercise, 13, 80-87.

Green, K. (2010). Key themes in youth sport. London: Routledge

Hansen, D. M., \& Larson, R. (2005). The youth experience survey 2.0: Instrument revisions and validity testing. Unpublished manuscript, University of Illinois at Urbana-Champaign. Retrieved from http://web.aces.uiuc.edu/youthdev/.

Hansen, D., \& Larson, R. (2007). Amplifiers of developmental and negative experiences in organized activities: Dosage, motivation, lead roles, and adultyouth ratios. Journal of Applied Developmental Psychology, 28, 360-374.

Hellison, D., \& Georgiadis, N. (1992). Basketball as a vehicle for teaching values. Strategies, 4(1), 1-4.

Hodge, K., \& Danish, S. (1999). Promoting life skills for adolescent males through sport. In A. M. Horne \& M. S. Kiselica (Eds.), Handbook of counseling boys and adolescent males: A practitioner's guide (pp. 55-71). Thousand Oaks, CA: Sage Publications

Holt, N. L. (2008). Positive youth development through sport. New York, USA: Routledge.

Holt, N. L., \& Jones, M. I. (2008). Future directions for positive youth development and sport research. In N. L. Holt (Ed.), Positive youth development through sport (pp. 122-132). New York, NY: Routledge.

Holt, N. L., Kingsley, B. C., Tink, L. N., \& Scherer, J. (2011). Benefits and challenges associated with sport participation by children and parents from low-income families. Psychology of Sport and Exercise, 12(5), 490-499.

Holt, N. L., \& Sehn, Z. L. (2008). Processes associated with positive youth development and participation in competitive youth sport. In N. L. Holt (Ed.), Positive Youth Development Through Sport (pp. 9-23). New York, NY: Routledge.

Janssens, J., \& van Bottenburg, M. (1999). Etnische tweedeling in de sport. Arnhem: NOC*NSF.

Lagendijk, E. (1991). De zwarte band van etnische minderheden. Over kleur, macht en kracht van lichaamscultuur. Vrijetijd en Samenleving, 9(2), 45-62.

Larson, R. (2000). Towards a psychology of positive youth development. American Psychologist, 55, 170-183.

Larson, R. W., Hansen, D. M., \& Moneta, G. (2006). Differing profiles of developmental experiences across types of organized youth activities. Developmental
Psychology, 42(5), 849-863.

Leffert, N., Benson, P., Scales, P., Sharma, A., Drake, D., \& Blyth, D. (1998). Developmental assets: measurement and prediction of risk behaviors among adolescents. Applied Developmental Science, 2(4), 209-230.

Lerner, R. M., Lerner, J. V., \& Benson, J. B. (2011). Advances in child development and behavior. Positive youth development. Amsterdam: Academic Press.

Lerner, R. M., Lerner, J. V., Almerigi, J. B., Theokas, C., Phelps, E., Gestdottir, S., \& von Eye, A. (2005). Positive youth development, participation in community youth development programs, and community contributions of fifth grade adolescents: Findings from the first wave of the 4-H study of positive youth development. Journal of Early Adolescence, 25, 17-71.

MacDonald, D., Côté, J., Eys, M., \& Deakin, J. (2012). Psychometric properties of the youth experience survey with young athletes. Psychology of Sport and Exercise, 13, 332-340.

Marsh, H., \& Kleitman, S. (2002). Extracurricular school activities: The good, the bad and the non-linear. Harvard Educational Review, 72(4), 464-514.

Nakeyshaey, M. T. (2005). Exploring Hip-Hop therapy with high risk youth. Praxis, 5, 30-36.

Partridge, J. (2011). Current directions in social influence: Parents and peers. Revista Iberoamericana de Psicología del Ejercicio y el Deporte, 6(2), 251-268

Perkins, D. F., \& Le Menestrel, S. (2007). New directions for youth development: Sports-based youth development. San Francisco: Jossey-Bass.

Peskin, H. (1967). Pubertal onset and ego functioning. Journal of Abnormal Psychology, 72, 1-15.

Petitpas, A. J., Cornelius, A. E., Van Raalte, J. L., Tiffany J. (2005). A framework for planning youth sport programs that foster psychosocial development. The Sport Psychologist, 19, 63-80.

Peugh, J. L. (2010). A practical guide to multilevel modelling. Journal of School Psychology, 48, 85-112.

Ramsahai, S. R. (2008). Thuiswedstrijd in een vreemd land: Een sociaal wetenschappelijke analyse van voetbal in eigen kring. [Home match in a foreign country: A social scientific analysis of soccer in their own circles]. Oisterwijk: Boxpress.

Rasbash, J., Charlton, C., Jones, K., \& Pillinger, R. (2009). Manual supplement for MLwiN Version 2.14. Centre for Multilevel Modeling, University of Bristol. Retrieved from http://www.bristol.ac.uk/cmm/soft ware/mlwin/download/supplement-print.pdf

Rhodes, J. E. (2005). A model of youth mentoring. In D. L. Du Bois \& M. J. Karcher (Eds.), Handbook of youth mentoring (pp. 30-43). Thousand Oaks, CA: Sage.

Riley, A. \& Anderson-Butcher, D. (2012). Participation in a summer sport-based youth development program for disadvantaged youth: Getting the parent perspective. Children and Youth Services Review, 34(7), 1367-1377. 
Rivera, M. T., Soderstrom, S. B., \& Uzzi, B. (2010). Dynamics of dyads in social networks: Assortative, relational, and proximity mechanisms. Annual Review of Sociology, 36(1), 91-115.

Sabo, D., \& Veliz, P. (2008). Go out and play: Youth sports in America. East Meadow, NY: Women's Sports Foundation.

Schaillée, H., \& Theeboom, M. (2014). Dansen = kansen voor meisjes in maatschappelijke kwetsbare posities. [Dancing = opportunities for girls in socially vulnerable situations.]. In B. Spruyt \& J. Siongers (Eds.), Gender(en): Over de constructie en deconstructie van gender bij Vlaamse Jongeren (pp. 83-98). Leuven: Acco.

Scheerder, J., Taks, M., \& Lagae, W. (2007). Teenage girls' participation in sports. An intergenerational analysis of socio-cultural predictor variables. European Journal for Sport and Society, 4(2), 133-150.

Smerdon, B.A. (2002). Students' perceptions of membership in their high schools. Sociology of Education, 75(4), 287-305.

Smith, A., Thurston, M., Green, K., \& Lamb, K. (2007). Young people's participation in extracurricular physical education: A study of 15-16 year olds in North-West England and North-East Wales. European Physical Education Review, 13(3), 339-368.

Smith, A. L. (2003). Peer relationships in physical activity contexts: A road less travelled in youth sport and exercise psychology research. Psychology of Sport and Exercise, 4, 25-39.

Steele, F. (2008). Module 5: Introduction to Multilevel Modelling MLwiN Practicals. Centre for Multilevel Modelling, University of Bristol. Retrieved from http://www.bristol.ac.uk/cmm/learning/modulesamples/5-practicals-mlwin-sample.pdf

Stevens, F., De Groof, S., \& Burssens, D. (2006). Uit de school geklapt: een 9 voor effectiviteit maar een 5 voor gelijkheid. Onderwijs in het jeugdonderzoek 2000-2005. In N. Vettenburg, M. Elchardus, \& L. Walgrave (Eds.), Jongeren van nu en straks. Overzicht en synthese van recent jeugdonderzoek in Vlaanderen (pp. 73-107). Leuven: LannooCampus.

Sumter, S., Bokhorst, C., Steinberg, L., \& Westenberg, P. (2009). The developmental pattern of resistance to peer influence in adolescence: Will the teenager ever be able to resist? Journal of adolescence,
32(4), 1009-1021.

Theeboom, M., P. De Knop, and P. Wylleman. 2008. Martial arts and socially vulnerable youth. An analysis of Flemish initiatives. Sport Education and Society, 13(3), 301-318.

Theeboom, M., Schaillée, H., \& Nols, Z. (2012). Social capital development among ethnic minorities in mixed and separate sport clubs. International Journal of Sport and Policy and Politics, 1(4), 1-21

Ullrich-French, S., \& Smith, A. L. (2009). Social and motivational predictors of continues youth sport participation. Psychology of Sport and Exercise, 10(1), 87-95.

Van Houtte, M., \& Van Maele, D. (2012). School is cool: the importance if faculty trust for student's social integration in technical/vocational versus academic schools. Kultura i Edukacja, 5(91), 103-127.

Verweel, P., Janssens, J., \& Roques, C. (2005). Kleurrijke zuilen-Over de ontwikkeling van sociaal kapitaal door allochtonen in eigen en gemengde sportverenigingen. [Colorful colums-Development of social capital by ethnic minorities in their own and mixed sport clubs]. Vrijetijdsstudies, 23(4), 7-22.

Vettenburg, N., \& Walgrave, L. (2009). Maatschappelijke kwetsbaarheid op school [Social vulnerability at school]. Welwijs, 20(3), 3-8.

Vogels, R., \& Bronneman-Helmers, R. (2000). Ontwikkelingen in het onderwijs en zelfstandigheid van leerlingen. In K. Wittebrood, \& S. Keuzenkamp (Eds.), Rapportage Jeugd 2000 (pp. 61-67). Den Haag: Sociaal en Cultureel Planbureau.

Weiss, C. H. (1998). Evaluation: Methods for studying programs and policies (2nd ed.). Upper Saddle River, NJ: Prentice Hall.

Weiss, M.R., Smith A.L., \& Theeboom, M. (1996). "That's what friends are for": Children's and teenagers' perceptions of peer relationships in the sport domain. Journal of Sport \& Exercise Psychology, 18, 347-379.

Wilkes, S., \& Côté, J. (2010). The developmental experiences of adolescent females in structured basketball programs. Physical \& Health Education Academic Journal, 2(2), 1-21.

Zarbatany, L., Ghesquiere, K., \& Mohr, K. (1992). A context perspective on early adolescents' friendship expectations. Journal of Early Adolescence, 12, 111-126.

\section{About the Authors}

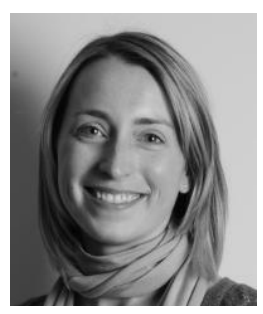

Hebe Schaillée

Hebe Schaillée holds a Master's degree in Physical Education (option Sport Management) and a teacher's certificate. She works as a doctoral researcher at the Faculty of Physical Education and Physical Therapy of the Vrije Universiteit Brussel, Belgium (VUB). Hebe is a member of the "Sport and Society" (SASO) Research Group. She has a special interest in the analysis of positive developmental outcomes that young people in general and disadvantaged youth in particular derive from their participation in organised sport. Her work focuses mainly on girls and women. 


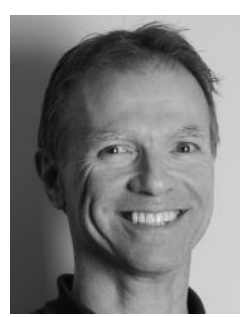

\section{Prof. Dr. Marc Theeboom}

Marc Theeboom holds a PhD in Physical Education and a Master's degree in Leisure Studies. He works as a full professor at the Vrije Universiteit Brussel, Belgium (VUB). He is chair of the "Sport and Society" Research Group and of the Department of Sport Policy and Management. Since 2010, he has been the promoter-coordinator of the Flemish Policy Research Centre for Sports (Steunpunt Sport). His research primarily focuses on policy-related and pedagogical aspects of sport in general as well as in relation to specific target groups in particular.

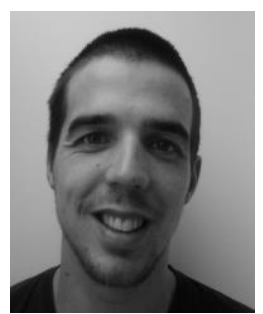

\section{Jelle van Cauwenberg}

Jelle van Cauwenberg holds a Master degree in Physical Education, a European Master degree in Health and Physical activity, and a teacher's certificate. Jelle works as a doctoral researcher at the Faculty of Medicine and Health Sciences of the Universiteit Gent and the Faculty of Physical Education and Physical Therapy of the Vrije Universiteit Brussel. His research primarily focuses on environmental determinants of physical activity for older adults. He is also involved in projects concerning sedentary behaviour, active transportation in children and adults and sport participation of disadvantaged youth. 